\title{
Synthesis of Inorganic pyrophosphatase-nanodiamond conjugates resistant to calcium and fluoride
}

Anastasiya V. Valueva ${ }^{1)}$, Roman S. Romanov ${ }^{2}$, Nataliya N. Vorobyeva ${ }^{3)}$, Svetlana A. Kurilova ${ }^{4)}$, Elena V. Rodina $\left.{ }^{3}\right)^{*}$

1) Pharmaceutical Department, Pavlov Ryazan State Medical University, 9 Vysokovol'tnaya St., Ryazan, 390026, Russia

2) Department of Fundamental Medicine, Lomonosov Moscow State University, 31, build. 5, Lomonosovsky prospect, Moscow, 119991, Russia

3) Chemistry Department, Lomonosov Moscow State University, 1, build. 3, Leninskie Gory, Moscow, 119992, Russia

4) A.N. Belozersky Institute of Physico-Chemical Biology, Lomonosov Moscow State University, 1, build. 40, Leninskie Gory, Moscow, 119992, Russia

\section{ABSTRACT}

Pyrophosphate arthropathy is the mineralization defect in human caused by the deposition of microcrystals of calcium pyrophosphate dihydrate in joint tissues. As a potential therapeutic strategy for the treatment of pyrophosphate arthropathy, delivery of exogenous pyrophosphate-hydrolyzing enzymes, inorganic pyrophosphatases (PPases), to the synovial fluid has been suggested. Previously, we synthesized the conjugates of E. coli PPase (Ec-PPase) with detonation synthesis nanodiamonds (NDs) as a delivery platform, obtaining the hybrid biomaterial retaining high pyrophosphatehydrolyzing activity in vitro. However, most known PPases including Ec-PPase in soluble form are strongly inhibited by $\mathrm{Ca}^{2+}$ ions. Since synovial fluid contains up to millimolar concentrations of soluble calcium, this inhibition might limit the in vivo application of Ec-PPase-based material in joint tissues. In this work, we proposed other bacterial PPase from Mycobacterium tuberculosis (MtPPase), which is resistant to the inhibition by $\mathrm{Ca}^{2+}$ ions, as an active $\mathrm{PP}_{\mathrm{i}}$-hydrolyzing agent. We synthesized conjugates of Mt-PPase with NDs and tested their activity under various conditions. Unexpectedly, conjugates of both Ec-PPase and Mt-PPase with aminated NDs retained significant 
hydrolytic activity in the presence of well known mechanism-based PPase inhibitors, fluoride or calcium. The incomplete inhibition of PPases by fluoride or calcium was found for the first time.

\section{Supporting Information}

Scheme and Equation S1. Activation of PPase with $\mathrm{Mg}^{2+}$ ion bound at the M2 site. E is the enzyme subunit, $\mathrm{S}$ is a substrate $\left(\mathrm{MgPP}_{\mathrm{i}}\right), \mathrm{EMg}^{2+}$ is the enzyme-magnesium complex with $\mathrm{Mg}^{2+}$ bound at the $\mathrm{M} 1$ site, $\mathrm{EMg}_{2}^{2+}$ is the enzyme-magnesium complex competent for substrate binding with $\mathrm{Mg}^{2+}$ bound at the M1 and M2 sites, $K_{d}$ is the dissociation constant of the $\mathrm{EMg}^{2+}{ }_{2}$ complex.

$$
\begin{gathered}
\mathrm{EMg}^{2+}+\mathrm{Mg}^{2+} \stackrel{K_{d}}{\longleftrightarrow} \mathrm{EMg}_{2}^{2+}+\mathrm{S} \leftrightarrow \mathrm{EMg}_{2}^{2+} \mathrm{S} \rightarrow \text { products } \\
A=\frac{A_{\max }\left[\mathrm{Mg}^{2+}\right]}{K_{d}+\left[\mathrm{Mg}^{2+}\right] \quad(\mathrm{S} 1),}
\end{gathered}
$$

where $A$ is the measured PPase activity, and $A_{\max }$ is the maximum activity.

Scheme and Equations S2. Reversible non-competitive complete $\left(k_{2}^{\prime}=0\right)$ or partial $\left(k_{2}^{\prime} \neq 0\right)$ inhibition of PPase, where $\mathrm{E}$ is the enzyme subunit (complexed with $\mathrm{Mg}^{2+}$ at the sites M1 and M2), S is a substrate $\left(\mathrm{MgPP}_{\mathrm{i}}\right)$, $\mathrm{I}$ is an inhibitor $\left(\mathrm{F}^{-}\right.$or $\left.\mathrm{Ca}^{2+}\right), K_{\mathrm{i}}$ is the inhibition constant, $k_{2}$ is the rate constant of the hydrolytic reaction in the absence of inhibitor, and $k_{2}^{\prime}$ is the limiting rate constant of the hydrolytic reaction in the presence of inhibitor.

$$
\begin{array}{cccccc} 
& \mathrm{E} & +\mathrm{S} & \leftrightarrow & \mathrm{ES} & \multicolumn{2}{l}{k_{2}} & \text { products } \\
& +\mathrm{I} & & +\mathrm{I} & & \\
K_{\mathrm{i}} & \uparrow & & \uparrow & & \\
& \mathrm{EI}+\mathrm{S} & \leftrightarrow & \mathrm{EIS} \stackrel{k_{2}^{\prime}}{\longrightarrow} \text { products }
\end{array}
$$

Equation for the inhibition of all PPases by $\mathrm{F}^{-}$and of immobilized PPases by $\mathrm{Ca}^{2+}$ :

$$
A=\frac{A_{0}\left(K_{\mathrm{i}}+\alpha \cdot \mathrm{I}\right)}{K_{\mathrm{i}}+\mathrm{I}}
$$


where $A$ is the measured PPase activity, $A_{0}$ is the PPase activity without inhibitor, $K_{\mathrm{i}}$ is the inhibition constant, $\alpha$ is the limiting ratio of $A$ to $A_{0}$, and I is the inhibitor concentration. In the case of complete inhibition $\alpha=0$, in the case of partial inhibition $\alpha \neq 0$.

Scheme and Equations S3. Reversible non-competitive complete $\left(k_{2}^{\prime}=0\right)$ or partial $\left(k_{2}^{\prime} \neq 0\right)$ inhibition of PPase, where $\mathrm{E}$ is the enzyme subunit (complexed with $\mathrm{Mg}^{2+}$ at the sites $\mathrm{M} 1$ and M2), $\mathrm{S}$ is a substrate $\left(\mathrm{MgPP}_{\mathrm{i}}\right)$, $\mathrm{I}$ is an inhibitor $\left(\mathrm{Ca}^{2+}\right), K_{\mathrm{i}}$ is the inhibition constant, $k_{2}$ is the rate constant of the hydrolytic reaction in the absence of inhibitor, and $k_{2}$ ' is the limiting rate constant of the hydrolytic reaction in the presence of inhibitor.

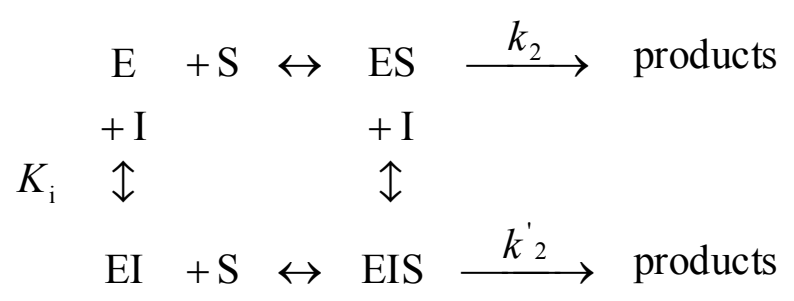

Hill equation for the inhibition of soluble PPases by $\mathrm{Ca}^{2+}$ :

$$
A=\frac{A_{0} K_{\mathrm{i}}^{h}}{K_{\mathrm{i}}^{h}+\mathrm{I}^{h}}
$$

where $A$ is the measured PPase activity, $A_{0}$ is the PPase activity without inhibitor, $K_{\mathrm{i}}$ is the inhibition constant, $h$ is the Hill coefficient, and I is the inhibitor concentration.

Scheme and Equation S4. The pH dependence of enzyme activity. ES is the enzyme-cofactorsubstrate complex, $K_{\mathrm{a} 1}$ and $K_{\mathrm{a} 2}$ are acidity constants of the titratable protein groups, and $m$ and $n$ are the number of titratable protons in the acid and alkaline $\mathrm{pH}$ ranges, respectively. 


$$
\begin{aligned}
& \text { ES } \stackrel{k_{2}^{\prime}}{\longrightarrow} \text { products } \\
& +n \mathrm{H}
\end{aligned}
$$

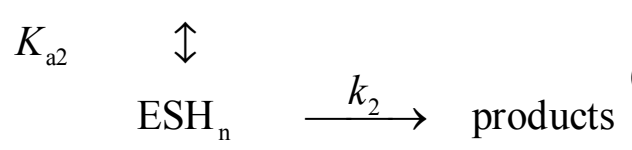

$$
\begin{aligned}
& +m \mathrm{H} \\
& K_{\mathrm{a} 1} \uparrow \\
& \mathrm{ESH}_{(\mathrm{m}+\mathrm{n})} \\
& A=\frac{A_{1}}{1+10^{m\left(\mathrm{p} K_{\mathrm{a} 1}-\mathrm{pH}\right)}+10^{n\left(\mathrm{pH}-\mathrm{p} K_{\mathrm{a} 2}\right)}}+\frac{A_{2}}{1+10^{n\left(\mathrm{p} K_{\mathrm{a} 2}-\mathrm{pH}\right)}}
\end{aligned}
$$

measured PPase activity, $A_{1}$ is a maximum activity (corresponding to the rate constant $k_{2}$ ), $A_{2}$ is the limiting level of activity in the alkaline range (corresponding to $k_{2}^{\prime}$ ). Limiting activity in the acidic range is zero.

Scheme and Equation S5. The pH dependence of hexamer stability monitored by PPase activity.

$$
\begin{aligned}
& \text { inactive } \\
& \text { oligomeric form } 1 \\
& +n \mathrm{H} \\
& K_{\text {a2 }} \uparrow \\
& \text { hexamer } \stackrel{k_{2}}{\longrightarrow} \text { products } \\
& +m \mathrm{H} \\
& K_{\text {al }} \uparrow \\
& \text { inactive } \\
& \text { oligomeric form } 2
\end{aligned}
$$

$$
A=\frac{A_{\max }}{1+10^{m\left(\mathrm{p} K_{\mathrm{a} 1}-\mathrm{pH}\right)}+10^{n\left(\mathrm{pH}-\mathrm{p} K_{\mathrm{a} 2}\right)}}(\mathrm{S} 5) \text { where } A \text { is the measured PPase activity, } A_{\max } \text { is the }
$$

maximum activity (rate constant $k_{2}$ ), $K_{\mathrm{a} 1}$ and $K_{\mathrm{a} 2}$ are acidity constants of the titratable protein groups controlling the stability of the hexamer, and $m$ and $n$ are the number of titratable protons in the acid and alkaline $\mathrm{pH}$ ranges, respectively. 